\title{
Building a Public Service Platform for Lifelong Education, Promoting the Development of an Education Service System for the Elderly
}

\author{
Weixia $\mathrm{Li}^{*}$ \\ Shanxi Radio \& TV University \\ Taiyuan, Shanxi, China
}

\section{Chen $\mathrm{Li}$}

Taiyuan University of Science and Technology Taiyuan, Shanxi, China

\begin{abstract}
The aging problem is increasingly serious in China. This paper explores the ways for old people open education development through the analysis of the elderly population growth trend, education status, and related policy support, the advantages of open education in our country. It is concluded to make use of information technology advantages, to build a lifelong education public service platform, and to develop "Internet plus education plus service", in a bid to realize the sharing and the equilibrium allocation of elderly education resources in urban and rural areas. All these measures meet the increasing demand for education for the elderly.
\end{abstract}

Keywords-Elderly People; Open Education for the Elderly; Public Service Platform of Online Lifelong Education; "Internet + Education + Service"

\section{INTRODUCTION}

By the end of 2018, the number of people aged 60 and above in China had reached 249.49 million, accounting for $17.9 \%$ of the total population. As the figure continues to grow, it is expected that it will have been close to 500 million by the 2050. The aging population will accelerate in the years near 2030. Forty years of reform and opening up have witnessed the rapid development of China's economy, dramatic changes in the social life, and rapid growth in spiritual culture and learning needs of groups at various stages. The elderly, in particular, are enthusiasm about learning mobilized by concepts like active old-age care, lifelong education and that it's never too late to learn. In the "Education Development Plan for the Elder People (2016-2020)", it is pointed out that the social resources should be integrated to spark vitality of the society, and that enable the elderly to enjoy the fruits of the reform and development by raising the modernization level of education for the aged, so as to ensure that the elderly have access to education, do what they want in the old ages and enjoy their life, and create a new pattern of education for the elderly with Chinese characteristics. It is put forward in "Opinions of the Ministry of Education and Other Nine Departments on Further Promoting the Development of Community Education" that more efforts should be made in the education for the elderly to increase participation and satisfaction in elder education. There will be broad space for the development of education for the aged.

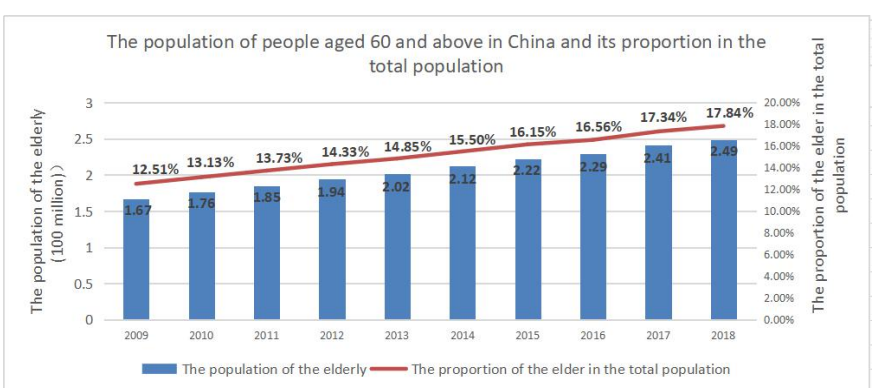

Fig. 1. The Growth Trend and Proportion of the Elderly Population in China in 10 Years

Education for the aged is an important part of open education and lifelong education in our country. Expanding the service form for the aged, developing education for the aged, especially developing open education for the aged, can effectively solve the contradiction between the learning needs of the aged group and the lack of learning resources, and is an integral part of building a learning-oriented society.

\section{ANALysis of EDUCATION NEEDS For THE AgED}

\section{A. The conflict between education services and needs of the} aged

As the elderly come to care the satisfaction of spiritual culture and learning needs, the slow development of service institutions and groups for the elderly, such as universities for the elderly, interest learning communities, falls behind the desire of continuing education for the elderly. At present, there are over 70 thousand educational institutions for the elderly, and 8 million old people are studying, about $3 \%$ of the total. It can be seen that there is a huge market for education with great demand. Whereas, the elderly participating in education generally belong to cities. The same is for high-quality education resources. The supply of the resources in rural and remote areas is too insufficient to meet the learning needs of the elderly in these areas. What's worse, there are also problems like the weak construction of the teaching team, unsystematic and untargeted curriculum system, and insufficient social efforts in the industry.

\section{B. Analysis of the characteristics of the elderly}

With the construction of a learning-oriented society, education for the aged in China has been endowed with the characteristics of a new era. At present, "active old-age care" is advocated to improve the happiness, sense of value and sense 
of achievement of the aged by providing diversified, personalized and professional services for them. From the physical condition of the elderly and their interaction with the world, their development can be divided into the stage of being able to take care of themselves and having benign interaction with the outside world, the stage of being incapable to take care of themselves and reluctant to contact the outside world, and the stage of needing others to take care of them and not being able to interact with the outside world. In China, 60 -year-old is seen as the starting point of the old. With the improvement of medical treatment, living standard and service level, people's life expectancy are prolonged, and they begin to pursue a higher level of spiritual enjoyment, and strive to achieve social needs, respect needs and self-realization. Generally, they hope to go back to life, enjoy life and find themselves self after retirement. Elderly people in the first stage are more willing to improve their life quality through learning, enrich their spiritual world and make up for the spiritual poverty in the era of material shortage.

\section{REQUIREMENTS OF THE TIMES: CREATING A LIFELONG EdUCATION PUBlic SERVICE PlatForm}

China attaches great importance to the use of information technology to deliver quality education resources to the wider community through the Internet. In October 2016, the "Education Development Plan for the Elder People (2016-2020)" issued by the state proposed that "we should use information technology to serve the aged education. Through the Internet, digital TV and other channels, we aim to strengthen quality senior learning resources in rural, remote, poverty-stricken and minority nationality areas". It is necessary for us to build the "Internet plus national elder education service platform", hence realizing the national old-age education development strategy.

Because of the operational ease of the smartphone, the convenience of carrying, and the immediacy of the Internet, the coverage and popularity of the smartphone have increased rapidly. By December 2018, China's Internet users reached 829 million, with an Internet penetration rate of $59.6 \%$; mobile netizen scale reached 817 million. In addition, society has gradually formed a strong atmosphere for seniors to learn from young people. The elderly are willing to accept fresh things and take the initiative to master advanced information technology. Chinese netizens continue to develop towards the middle-aged group. In 2018, netizens aged 60 and above accounted for $6.6 \%$ of the total, about 54.714 million, accounting for $22 \%$ of the national elderly population. The uneven distribution of educational resources in China can be effectively solved by means of the Internet, mobile terminal equipment, and communication technologies. From the national level, it is feasible to utilize the Internet $5 \mathrm{G}$ technology to create an "Internet plus national senior education service platform". The country has the capability to concentrate on big issues, and the state also strongly supports people's livelihood projects and emphasizes lifelong education for all.

In the process of developing lifelong education, elderly education and open education, the Open University has been entrusted with the important task of the Times. The Open
University boasts of the advantage of running schools systematically. Forty years of development witnessed the extension of school-running network to all counties in the country. There are abundant educational resources that can be coordinated as a whole, which is an ideal platform to develop education for the aged. Relying on the Open University and combining with the educational network of the national TV University system, we will build a national education service platform for the aged, which can pool high-quality education resources for the senior in China. Through the Internet, we can break through space and time restrictions, present high-quality education resources to the elderly in a timely and immediate manner, and provide superior "online plus offline" education resources and services for the elderly across the country, hence achieving balanced development of education for the old people.

\section{EXPlore the DeVElopment PATH OF Open EdUCATION FOR THE AGED}

The development of open education for the elderly should be based on the basic national conditions, follow the rules of education for the aged, adhere to reform and innovation, closely combine the Internet cloud technology with open education, and build a system with the resources of radio and television universities in various provinces and cities: public service system of lifelong education for all; create a platform: lifetime education public service platform; grasp two main lines: academic education and non-academic education; strengthen the three pillars of support: talent support, technical support, and resource support. We will strive to deliver high-quality resources to the elderly in urban, rural, and remote and poverty-stricken areas to ensure that education for the senior is fully covered.

\section{A. Relying on the construction of public service platform for lifelong education to carry out rich and diverse services for the old people}

1) Construct resource management sub-platform. The resource management sub-platform includes the resource base of teachers and experts for elderly education, education and teaching, scientific research projects, volunteers, social organizations and elderly services. We should do a good job in the basic work of building the resource bank for education and teaching for the aged, fully pool the high-quality domestic resources, build a resource bank for senior education with high-quality resources, complete subjects, rich contents and diverse forms to effectively realize the integration, sharing, co-construction and intelligent push of the educational resources for the aged. In addition, we should actively explore and develop local resources such as excellent traditional culture, folk culture and regional culture with regional characteristics to provide quality learning resources close to reality and life for the elderly groups all over the country.

2) Build learning and management sub-platform. Learning and management platform is a comprehensive network platform integrating learning, management and support services. We should give full play to the advantages of the hierarchical school-running network system of TV 
University, and build an online learning network of the elderly education covering both urban and rural areas through intelligent learning environment of the learning platform; the elderly education and learning support service system can be constructed through the hierarchical authorized management mechanism of the learning platform. We will develop "online plus offline" education services for the elderly through a nationwide education network and offline senior experience centers that extend to communities and villages.

3) Construct school credit bank sub-platform. We will improve the storage and transformation mechanism and mode of school credit bank, and provide channels for the accumulation and conversion of education and learning approaches, learning forms and achievements for the aged at all levels, making the learning achievements of the aged more flexible and convenient. We should establish a reward system to continuously improve the sense of gain and achievement of learning. Through school credit bank, we can establish communication channels between academic education and non-academic education. The flexible school system and learning form can fully meet the different needs of the elderly, and provide opportunities for aged learners to obtain corresponding academic certificates.

4) Sub-platform for elderly service. $5 \mathrm{G}$ technology will be utilized to build a convenient and one-stop service platform incorporating financial services, family pension services, medical services for the aged, tourism services for the elderly and cultural and entertainment services for the old people.

5) Take sub-platform for big data analysis and display and decision-making. The platform integrates the underlying data of various application systems across the country, provides big data analysis, display and integrated management in various fields of elderly services, offering big data support and basis for national and local governments to make decisions on elderly undertakings.

\section{B. Relying on the open university to promote the construction of "internet plus education plus service" system}

China's Open University is systematically running; branch schools and academic positions are covered by provinces, cities and counties and rich educational resources can be coordinated, which is an ideal platform for the development of senior education. We can build on the advantages of the Open University system to build an "Internet plus education plus service" system. By the application of the Internet, 5G technology and big data cloud computing publishing platform to organically integrate elderly open education, pension service, community service, medical service, volunteer service and social work agency service to achieve seamless combination, namely to offer teaching service with priority to lifelong education and living service with endowment as supplement, realizing the integration of point and sphere and network coverage. We should combine elderly education service with basic pension service, old-age Open University construction with pension service, building the "Internet plus education plus service" system closely related to the elderly daily requirements.

\section{Build the "online plus offline" education and learning mode for the elderly by relying on the advantages of the open education system}

We should carry out "online plus offline" education and learning mode for the aged. Through online registration, network resources and service projects can be opened to the whole society by using various online terminal forms such as computer, mobile phone, Pad, and other mobile devices and electronic propaganda screen. On the basis of online registration of the learning platform, we provide personalized guidance and tutoring services according to the needs of learners. We carry out various forms of online learning education activities, highlighting the diversity, flexibility, and universality of education for the elderly. In line with the principle of "highlighting the online and grasping offline", we will develop offline education services. Relying on community and old-age service institutions, we will build community, urban and rural old-age care institutions and rural elderly experience centers, and develop "online plus offline" senior education services. We will introduce new technologies and devices such as smart wearable devices, robots and home assistants into experiential teaching activities to enhance the effect of offline education services.

\section{Strengthen cooperation and exchanges among colleges and universities to provide talent support for the development of senior education}

We will build institutions of senior education services in colleges and universities, fully integrate the resources of teachers and education related to it, and provide intellectual support for the development of senior education. Relying on the resources of local colleges and universities, we aim to establish a talent pool of experts of local senior education. We will encourage research on education and teaching for the aged and increase support for theoretical research on senior education. We will build a scientific research mechanism, strengthen cooperation and exchanges among colleges and universities, and constantly improve the level of education and research for the elderly. We will increase projects related to education to provide scientific theoretical basis and guidance for the development of senior education. We will carry out training for senior education personnel; establish a regular training mechanism for senior education workers, standards for assessing their abilities and requirements for social services, hence constantly improving their lecturing skills, scientific research and innovation capabilities.

\section{E. Accelerate the formulation of laws and regulations on senior education to offer legal guarantee for its development}

Some developed countries that entered the aging society at a relatively early time have formulated laws and regulations on elderly education, ensuring the right to receive education by laws and regulations and giving old education grants and reducing school fees by expanding the elderly education channels. In this way, every work of old age education can be advanced smoothly and become mature gradually. For example, the UK attaches great importance to protecting the learning rights of vulnerable elderly people, and provides educational opportunities for the elderly with family burdens, 
the elderly living alone and living in remote areas, teaching the concept, learning programs and courses of distance education to the elderly living alone and living in remote areas. China's elderly education started late, and the formulation of laws is lagging behind. Against the backdrop of comprehensively promoting the rule of law, it is imperative to promote the healthy and rapid development of education for the aged by using legal thinking and methods and accelerate the legislation of senior education. China's current legal and regulatory documents on elderly education mainly include "The Education Law of the People's Republic of China", "Rights Protection Law of the People's Republic of Elderly", and "The Law in Elderly". Tianjin issued the "Elderly Education Regulations" in 2002 and it was China's first local regulations of senior education. All provinces should speed up the integration of education for the aged into the legal system, and clarify functions of relevant departments, functional positioning, channels, management mechanism, government funding input and resource guarantee of elderly education through policies and regulations.

\section{CONCLUSION}

In a nutshell, as China's old people education is in great demand, the market is huge. It is viable to leverage advanced information technology to create a public service platform for lifelong education, launch the pattern of "internet + education + service" to provide senior citizens with high-quality online education resources and personalized services. By addressing the unbalanced distribution of education resources and unbalanced development of elderly education and the resources shortage, more old people are able to learn what they want, which accelerating the construction of a learning-oriented society.

\section{ACKNOWLEDGMENT}

I would like to express my gratitude to Professor Li Chen for his patient guiding and help. It is he who enlightens me and guides me to look further into the development of open education for the elderly, thanks to which I have a clearer understanding of how to build a lifelong education service platform, combined with the development of modern information technology.

\section{REFERENCES}

[1] National Bureau of Statistics. The 2018 Statistical Communique on National Economic and Social Development [EB/OL] (2018-02-28).http://www.stats.gov.cn/tjsj/zxfb/201902/t20190228_1651 265.html.

[2] ZhiYan. 2018-2024 China Pension Industry Market Research and Investment Prospects Analysis Report. http://www.chyxx.com/industry/201801/605554.html.

[3] Development Plan for the Elder People (2016-2020)" [EB/OL] (2016-10-19).http://www.gov.cn/zhengce/content/2016-10/19/content_5 121344.htm.

[4] Opinions of the Ministry of Education and Other Nine Departments on Further Promoting the Development of Community Education[EB/OL]. (2016 -07 -08).

http://www.edu.cn/edu/zheng_ce_gs_gui/zheng_ce_wen_jian/zong_he/2 01607/t20160727_1434396.shtml.

[5] CNNIC. Statistical Report on the Development of the Internet in China[EB/OL].(2019-02). http://cnnic.cn/gywm/xwzx/rdxw/20172017_7056/201902/t20190228_7 0643.htm.

[6] Lou Zhengrong. Analysis and Enlightenment of Foreign Aged Education Policy [J]. Continue Education Research, 2012-08-15. 